\title{
Enhancement of Infectivity of a Non-Syncytium Inducing HIV-1 by sCD4 and by Human Antibodies that Neutralize Syncytium Inducing HIV-1
}

\author{
M. SChUtTEN, A. C. ANDEWEG ${ }^{* \dagger}$, M. L. BOSCH* ${ }^{*}$, A. D. M. E. OSTERhAus \\ Erasmus University Rotterdam, Institute of Virology, Rotterdam, The Netherlands \\ *National Institute of Public Health and Environmental Protection, Bilthoven, The Netherlands
}

\begin{abstract}
Schutten M, Andeweg AC, Bosch ML, Osterhaus ADME. Enhancement of Infectivity of a NonSynctium-Inducing HIV-1 by SCD4 and by Human Antibodies that Neutralize Syncytium-Inducing HIV-1. Scand J Immunol 1995;41:18-22

Enhancement of virus infectivity after SCD4 treatment has been documented for SIVagm and HIV-2. It has been suggested that a similar phenomenon may play a role in HIV-1 infection. In the present study we have analysed biological activities of virus neutralizing polyclonal and monoclonal human antibodies and of sCD4, towards HIV-1 chimeras with envelope proteins derived from one donor, which display different biological phenotypes. The antibodies, which recognize the V3 and/or the CD4 binding domains of the glycoproteins of these viruses and also SCD4 showed different levels of virus neutralizing activity toward the syncytium inducing HIV-1 strains. In contrast, they all dramatically enhanced the infectivity of an HIV-1 chimera with an envelope glycoprotein displaying the non-syncytium-inducing phenotype. Given the relatively conserved nature of non-syncytium-inducing HIV-1 surface glycoproteins early after infection, these data suggest a major role for antibody mediated enhancement of virus infectivity in the early pathogenesis of HIV-1 infection.
\end{abstract}

Professor $\operatorname{Dr}$ A. D. M. E. Osterhaus, Erasmus University Rotterdam, Institute of Virology, Dr Molewaterplein 50, P.O. Box 1738, 3000 DR Rotterdam, The Netherlands

\section{INTRODUCTION}

The identification and characterization of virus neutralization inducing (VNI) antigenic sites on the glycoproteins of HIV-1 have been the focus of many studies (for review see [1]). For practical reasons, HIV-1 strains and primary HIV-1 isolates which efficiently replicate in $\mathrm{T}$ cells have predominantly been used to study virus neutralization [1]. In this context it is important to note that macrophage-tropic non-syncytiuminducing (NSI) variants with low efficiency of replication in T cells predominate in the asymptomatic stage and $\mathrm{T}$ cell linetropic syncytium inducing (SI) variants are almost exclusively found in late stages of the infection [2,3]. The macrophagetropic NSI strains have been shown to exhibit a relatively high level of conservation in their VNI V3 loop [4]. It has been suggested that escape from virus neutralizing (VN) antibodies is based on the relatively high mutation rate generally

† Current address: BPRC, Lange Kleiweg 151, 2288 GJ Rijswijk, The Netherlands.

¥Current address: Regional Primate Research Center, I-421 Health Sciences Center SJ-50, University of Washington, Seattle WA 98195, USA. observed in the virus envelope glycoprotein. Given the fact that also the CD4 binding domain (bd) is relatively conserved, another mechanism of escape from $\mathrm{VN}$ antibodies may be postulated for the relative success of NSI/macrophagetropic viruses to persist in the host. To study the basis of this apparent paradox, we have used an env complementation assay in which the biological activities could be compared of human HIV-1-specific monoclonal and polyclonal antibody preparations towards identical HIV-1 strains only differing in their glycoproteins which displayed an SI or an NSI phenotype.

\section{MATERIALS AND METHODS}

Human antibodies, sCD4 and HIV-1 envelope glycoproteins. The human monoclonal antibodies (HuMoAbs) used are directed against the CD4 binding domain (GP13 and GP68 [5]), a highly conserved conformational epitope on gp41 (K14 [6]) and the HIV-1 gp120 V3 loop (257-D [7]). Furthermore sCD4 (kindly provided by Dr I. Jones through the MRC AIDS directed programme) and HIVIG [8]) (kindly provided by Dr H. Schuitemaker) were used as VN agents. The env genes used [16.1 (SI), 16.2 (SI), 16.4 (NSI), MN and IIIB] for 
the production of envelope glycoproteins in the capture antibody ELISA and for the production of chimeric viruses have previously been characterized and described [9, 10-12].

Capture antibody ELISA for measurement of relative affinity. The relative affinity of the HuMoAbs used in the present study was determined in a previously described ELISA. In short, ELISA plates (Costar, Cambridge, MA 02140, USA, cat. no, 3590), coated with affinity purified sheep immunoglobulins directed against the carboxy terminus of gp120 (Aalto BioReagents, Dublin, Ireland, cat. no. D7324), were incubated for $2 \mathrm{~h}$ with cell lysate of recombinant vaccinia virus (rVV) infected HELA [13] cells (16 (NSI) and 16 (SI)) or HIV-1 infected SupT1 [14] cells (MN [11] and IIIB [12]). Plates were subsequently washed and incubated with serial dilutions of previously described HuMoAbs (GP13, GP68 [5] and 257-D [7]). The ELISA was completed and read as previously described [10]. The relative amount of antigen bound to the ELISA plates was calibrated by using the same ELISA protocol with serial dilutions of the antigen and a standard excess concentration of polyclonal serum from seropositive individuals. The data presented are the mean values of duplicates in one assay which was performed at least twice with similar results.

Envelope trans-complementation assay. This assay was based on a previously described trans-complementation assay in which an envdefective HIV-1 provirus, encoding the bacterial CAT reporter gene [15], was complemented for a single round of replication by a set of recently described HIV-1 envelope glycoproteins [9]. The env genes encoding these glycoproteins were derived from biologically cloned SI or NSI viruses, isolated from one single donor (number 16) at a single point in time in natural target cells (peripheral blood mononuclear cells [PBMC]). In the complementation assay the genes encoding these envelope glycoproteins were co-transfected into a $\mathrm{CD}^{-}$cell line (COS [16]) together with the env-defective molecular clone of the HIV-1 IIIB strain. This resulted in the production of virions carrying heterologous envelope glycoproteins which could infect $\mathrm{CD}^{+}{ }^{+}$cells, like the SupT1 cells or PHA stimulated PBMC used in this study. After 3 days cell free supernatants were collected

Table 1. Relative affinities of HuMoAbs for different HIV-1 envelope glycoproteins

\begin{tabular}{|c|c|c|c|c|c|c|}
\hline \multirow[b]{2}{*}{$\mathrm{HuMoAb}$} & \multirow[b]{2}{*}{ Specificity } & \multicolumn{5}{|c|}{ HIV-1 strain (phenotype) } \\
\hline & & $\begin{array}{l}16.1 \\
\text { (SI) }\end{array}$ & $\begin{array}{l}16.2 \\
\text { (SI) }\end{array}$ & $\begin{array}{c}16.4 \\
(\mathrm{NSI})\end{array}$ & $\begin{array}{c}\mathrm{MN} \\
\text { (SI) }\end{array}$ & $\begin{array}{l}\text { IIIB } \\
\text { (SI) }\end{array}$ \\
\hline K14 & gp41 & $83^{*}$ & 67 & 67 & 33 & 67 \\
\hline GP13 & CD4 bd & 83 & 83 & 33 & 250 & 250 \\
\hline GP68 & CD4 bd & 67 & 67 & 67 & 125 & 250 \\
\hline 257-D & V3 domain & 125 & 125 & 125 & 125 & $-{ }^{\dagger}$ \\
\hline
\end{tabular}

\footnotetext{
* Reciprocal of dilutions of MoAbs, starting at $1 \mu \mathrm{g} / \mathrm{ml}$, still giving $50 \%$ of maximal binding with the respective envelope glycoproteins in a capture antibody ELISA as a measure of relative affinity. The data presented are the mean values of duplicates in one assay which was performed at least twice with similar results.

$\uparrow$ No binding: OD450 $\mathrm{nm}$ values remained at background levels at the concentrations tested.
}

by centrifugation and frozen at $-135^{\circ} \mathrm{C}$. For infection the amount of p24 antigen, as determined with a p24 ELISA kit (V5, Organon Teknika, Boxtel, The Netherlands) was calibrated and the level of envelope expression was checked with the capture antibody ELISA (see above). Infection was performed overnight at $37^{\circ} \mathrm{C}$ in $1 \mathrm{ml}$ medium. After $24 \mathrm{~h}$ the cells were washed and cultured for $72 \mathrm{~h}$. CAT activity in these cells was measured in a previously described CAT assay using a two-phase extraction system [17]. CAT activities expressed in the cells were considered a direct measure of virus infectivity in these assays.

\section{RESULTS}

\section{Relative affinity of HuMoAbs for HIV-1 envelope glycoproteins}

The HuMoAbs used in these experiments were selected on basis of their epitope specificities and relative affinities in the capture antibody ELISA for different HIV-1 envelope glycoproteins (Table 1). The same recombinant envelope glycoproteins were used in the env complementation assay (Table 2). Both CD4 bd specific HuMoAbs GP13 and GP68 showed an overall higher relative affinity for the glycoproteins of the T cell line adapted HIV-1 strains IIIB and MN than for the glycoproteins derived from the donor number 16 HIV-1 strains. The V3 loop specific HuMoAb 257-D showed a high relative affinity for the glycoproteins of the MN-like HIV-1 strains and no binding was observed in this ELISA with the glycoproteins of HIV-1 IIIB (Table 1).

\section{Virus neutralization and enhancement of viral infectivity by sCD4 and human antibodies}

The VN activities of human antibodies and SCD4 toward T cell line adapted strains HIV-1 MN and HIV-1 IIIB (Table 2) have been documented previously [10-13]. The CD4 bd specific HuMoAbs GP13 and GP68 as well as HIVIG and sCD4, inhibited infectivity of HIV-1 16.2 (SI) only to a limited extent $(<50 \%)$ when tested at a concentration $(15 \mu \mathrm{g} / \mathrm{ml})$ that significantly inhibited infectivity of HIV-1 IIIB in the env complementation assay (reduction to $15 \%$, $12 \%, 9 \%$ and $8 \%$ respectively) (Table 2 ). The V3 domain specific $\mathrm{HuMoAb}$ tested at the same concentration, neutralized HIV-1 16.2 (SI), as was shown by a reduction of CAT activities to $0.7 \%$ (Table 2 ). No major biological activity of any of the antibodies tested or SCD4, was observed against HIV-1 16.1 (SI) as was shown by a reduction of CAT activity with $2-9 \%$ only, using $15 \mu \mathrm{g} / \mathrm{ml}$ antibody (Table 2 ).

In contrast to the $\mathrm{VN}$ activities observed with the SI viruses, the same concentration of all these $\mathrm{VN}$ antibodies and SCD4 caused a dramatic enhancement of infectivity of HIV-1 16.4 which has a NSI envelope (> six-fold increase in CAT activity) (Table 2). In order to demonstrate the dose dependency of these phenomena, dose response curves were made with the V3 domain specific HuMoAb 257-D, which exhibited the highest affinity for all the envelop proteins 
Table 2. Virus neutralizing and enhancement activities of human antibody preparations and sCD4

\begin{tabular}{|c|c|c|c|c|c|c|c|}
\hline \multirow[b]{2}{*}{ Antibody preparation } & \multirow[b]{2}{*}{ Epitope } & \multirow[b]{2}{*}{$\begin{array}{c}\mathrm{MN}^{*} \\
\text { (SI) }\end{array}$} & \multicolumn{4}{|c|}{ Virus strain (biological phenotype) } & \multirow[b]{2}{*}{$\begin{array}{c}16.4 \\
\text { (NSI) }\end{array}$} \\
\hline & & & $\begin{array}{l}\text { IIIB } \\
\text { (SI) }\end{array}$ & $\begin{array}{l}\text { IIIB } \\
\text { (SI) }\end{array}$ & $\begin{array}{l}16.1 \\
(\mathrm{SI})\end{array}$ & $\begin{array}{l}16.2 \\
(\mathrm{SI})\end{array}$ & \\
\hline none & & $-\ddagger$ & - & $\begin{array}{l}100^{\S} \\
72.461^{*}\end{array}$ & $\begin{array}{l}100 \\
55.065\end{array}$ & $\begin{array}{l}100 \\
54.428\end{array}$ & $\begin{array}{l}100 \\
8.239\end{array}$ \\
\hline K14 & gp41 & - & - & 103 & 98 & 106 & 96 \\
\hline GP13 & CD4 bd & + & + & 15 & 97 & 65 & 732 \\
\hline GP68 & CD4 bd & + & + & 12 & 93 & 65 & 741 \\
\hline sCD4 & CD4 bd & + & + & 9 & 92 & 84 & 620 \\
\hline 257-D & V3 & + & - & 97 & 91 & 0.7 & 655 \\
\hline \multirow[t]{2}{*}{ HIVIG } & poly & + & + & 8 & 95 & 95 & 744 \\
\hline & & \multicolumn{2}{|c|}{$\mathrm{VN}$ assay } & \multicolumn{3}{|c|}{ env complementation assay } & \\
\hline
\end{tabular}

$\ddagger$ Due to differences in the VN assays used, biological activities are indicated as high $(+)$ or undetectable $(-)$.

$\S$ Percentage of CAT activity relative to the CAT activity observed in the absence of antibody. The mean value within one experiment obtained with SupT1 cells is given. The antibody preparations were tested at least twice with the same chimeric virus yielding similar results.

*CAT activity in counts per minute $(\mathrm{cpm})$, background values range from 300 to $800 \mathrm{cpm}$.

tested (Table 1). Clear dose related VN and enhancement activities were found with this antibody in the env complementation assay with HIV-1 16.2 (SI) and HIV-1 16,4 (NSI) respectively (Fig. 1). When these experiments were repeated in PHA stimulated PBMC essentially the same phenomena were observed. The overall differences were however less pronounced in this system (average enhancement about $50 \%$ ) probably due to a limited cellular host range of this virus (A. C. Andeweg et al, unpublished observations).

\section{DISCUSSION}

Using an assay that is highly sensitive for measuring viral entry we have shown in the present study that both SCD4 and human antibodies which neutralize SI HIV-1 strains may enhance infectivity of NSI HIV-1 strains.

HIVIG, sCD4 and the CD4 bd specific HuMoAbs GP13 and GP68 readily neutralized the HIV-1 IIIB strain whereas limited or no VN activity was observed against the primary HIV-1 strains from donor number 16. This supports previous observations that sCD4, CD4 bd specific HuMoAbs and HIVIG have little or no neutralizing activity against primary virus strains (M. Schutten, personal observation and [18]). It has been shown by several groups that VN capacity of V3 loop specific MoAbs toward T cell line adapted HIV-1 strains is dependent on the affinity of the antibody for the V3 loop of the HIV-1 strain used [7, 19]. However, in the present study we showed that VN activity of V3 loop specific HuMoAb 257-D toward the SI HIV-1 strains from donor number 16 is not directly related to its relative affinity for the glycoproteins involved: identical relative affinities for the 16.1 (SI) and 16.2 (SI) envelope glycoproteins were observed, but reductions in the env complementation assay proved to be 9 and $99.3 \%$ respectively. This was unexpected since both envelopes exhibit SI capacity and a $95 \%$ overall predicted amino acid sequence homology exists between these envelopes [9]. Since we have previously shown that other domains than the V3 domain are involved in membrane fusion [10], it may be speculated that HIV-1 16.1 is less dependent on the V3 domain to establish membrane fusion and infection.

The efficiency of entry into T cell lines of the NSI HIV-1 strain 16.4 was significantly lower than that of the SI HIV-1 strains 16.1 and 16.2 as shown by a $>$ six-fold lower CAT activity. The infectivity of the NSI HIV-1 strain was however enhanced to levels comparable to those of the SI HIV-1 strains by the administration of sCD4 or antibodies that neutralized these SI HIV-1 strains. Different mechanisms for HIV-1 specific antibody mediated enhancement have been described, including Fc receptor- and complementmediated enhancement $[20,21]$. Two observations argue against the same mechanism in our experiments. Firstly, SupT1 cells do not express Fc receptors [14] and complement was not present in the assays. Secondly, enhancement of HIV116.4 (NSI) was also observed with sCD4 (Table 2). An explanation for the observed enhancement can be found in a mechanism previously described for the enhancement of noncytopathic SIV agm infectivity and induction of HIV-2 mediated cell fusion of CD4 $4^{-}$cells, by sCD4. In these systems sCD4 does not induce dissociation of surface glycoprotein (SU) from infected cells [22, 23]. In contrast, sCD4 does 


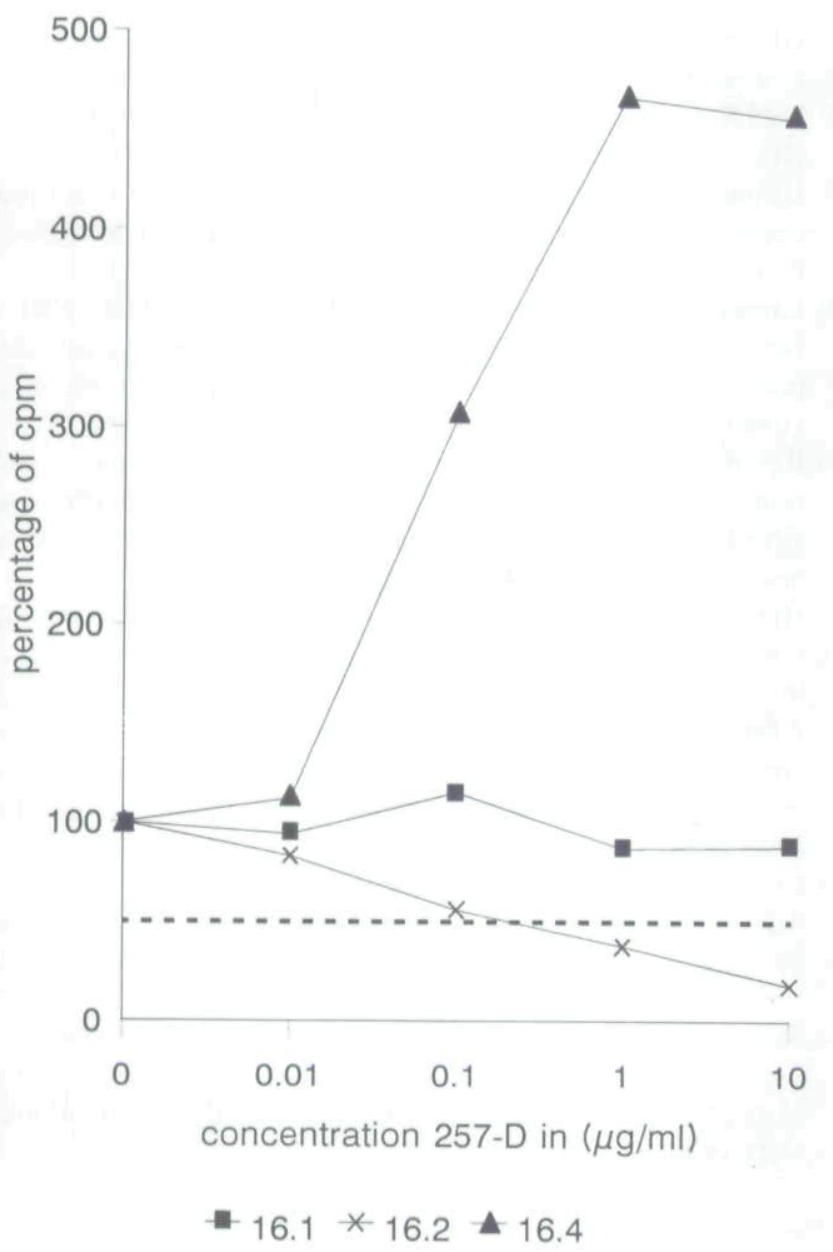

Fig. 1. Virus neutralizing and infectivity enhancing activities of serial dilutions of HuMoAb 257-D using SupT1 cells in the env complementation assay with HIV-1 16.1 (SI), HIV-1 16.2 (SI) and HIV-1 16.4 (NSI) chimeric viruses. Counts per min (cpm) obtained in the assays with antibodies, are expressed as percentages of cpm obtained in the assay carried out in the absence of antibodies. Dotted line represents $50 \%$ inhibition of virus infectivity.

induce dissociation of SU from cells infected with $\mathrm{T}$ cell line adapted HIV-1 strains which are readily neutralized by sCD4 [24]. We hypothesize that both sCD4 and the antibodies we studied, cause conformational changes in the viral envelope complex of certain NSI/macrophage-tropic HIV-1 strains exposing cryptic fusion sites as was also shown in the SIVagm and HIV-2 systems [22, 23]. These changes would allow a more efficient virus-cell fusion that is less dependent on the presence of $\mathrm{CD} 4$ on the target cell membrane.

Taken together our data suggest that naturally occurring antibodies to the so-called HIV-1 VNI antigenic sites, may cause either neutralization or enhancement dependent on the biological phenotype of the virus recognized. If indeed our findings are a reflection of a more general phenomenon of enhancement also found in infections with other lentiviruses like HIV-2 [23] and SIVagm [22], they may explain why early after HIV-1 infection predominantly viruses with an NSI/ macrophage-tropic phenotype are found and why these viruses are able to persist in the infected host despite the conserved nature of their ' $\mathrm{VNI}$ ' antigenic sites. The observed enhancement would actually favour replication of viruses displaying the NSI/macrophage-tropic phenotype, whereas viruses displaying the SI/T cell line-tropic phenotype are neutralized.

These observations may not only have implications for our understanding of the pathogenesis of HIV-1 infection but also for the development of immunization strategies. If this observation is the reflection of a more general phenomenon, the induction or administration of antibodies that neutralize viruses of the SI/T cell-tropic phenotype, which is a commonly followed strategy at present, may actually be counter productive.

\section{ACKNOWLEDGMENTS}

We thank Professor Dr J. G. Sodroski for supplying the vector used in the env complementation assay, Dr E. Hunter for the PSRHS vector, Drs S. Zolla-Pazner and M. K. Gorny for supplying the V3 domain specific HuMoAb 257-D, the AIDS-Directed Programme of the Medical Research Counsil for supplying the sCD4 and Drs G. Rimmelzwaan and R. Gruters for critically reading the manuscript. Furthermore, we thank Ms C. W. H. M. Kruyssen for secretarial assistance. The work was supported by the Dutch organization for Scientific Research (NWO) and the Dutch Advisory Counsel on Health Research (RGO).

\section{REFERENCES}

1 D'Souza MP, Geyer SJ, Hanson CV et al. Evaluation of monoclonal antibodies to HIV-1 envelope by neutralization and binding assays: an international collaboration. AIDS 1994;8:196-81.

2 Zhu T, Mo H, Wang $\mathrm{N}$ et al. Genotypic and phenotypic characterization of HIV-1 patients with primary infection. Science 1993;261:1179-81

3 Zhang LQ, MacKenzie P, Cleland A, Holmes EC, Brown AJ, Simmonds P. Selection for specific sequences in the external envelope protein of human immunodeficiency virus type 1 upon primary infection. J Virol 1993;67:3345-56.

4 Chesebro B, Wehrly K, Nishio J, Perryman S. Macrophagetropic human immunodeficiency virus isolates from different patients exhibit unusual V3 envelope sequence homogeneity in comparison with $\mathrm{T}$ cell-tropic isolates: definition of critical amino acids involved in cell tropism. J Virol 1992;66:6547-54.

5 Schutten M, McKnight A, Huisman RH et al. Further characterization of an antigenic site of HIV-1 gp120 recognized by virus neutralizing human monoclonal antibodies. AIDS 1993;7:91923.

6 Teeuwsen VJP, Siebelink KH, Crush-Stanton S et al. Production and characterization of a human monoclonal antibody, reactive with a conserved epitope on gp41 of human immunodeficiency virus type I. AIDS Res Hum Retrovirus 1990;6:381-92. 
7 Gorny MK, Xu J-Y, Karwowska S, Buchbinder A, Zolla-Pazner S. Repertoire of neutralizing human monoclonal antibodies specific for the V3 domain of HIV-1 gp120. J Immunol 1993; 150:635-43.

8 Prince AM, Horowitz B, Baker L et al. Failure of a human immunodeficiency virus (HIV) immune globulin to protect chimpanzees against experimental challenge with HIV. Proc Natl Acad Sci USA 1988;85:6944-8.

9 Andeweg AC, Groenink M, Leeflang P et al. Genetic and functional analysis of a set of HIV-1 envelope genes obtained from biological clones with varying syncytium-inducing capacities. AIDS Res Hum Retrovirus 1992;8:1803-13.

10 Andeweg AC, Leeflang P, Osterhaus ADME, Bosch ML. Both the $\mathrm{V} 2$ and $\mathrm{V} 3$ regions of the human immunodeficiency virus type 1 surface glycoprotein functionally interact with other envelope regions in syncytium formation. J Virol 1993;67:3232-9.

11 Gallo RC, Salahuddin SZ, Popovic M et al. Frequent detection and isolation of cytopathic retroviruses (HTLV-III) from patients with AIDS and at risk for AIDS. Science 1984;224:500-3.

12 Popovic M, Sarngadharan MG, Read E et al. Detection, isolation, and continuous production of cytopathic retroviruses (HTLV-III) from patients with AIDS and pre-AIDS. Science 1984;224:497-500.

13 Scherer ZwF, Syverton JT, Gey GO. Studies on the propagation in vitro of poliomyelitis viruses. J Exp Med 1953;97:695-709.

14 Smith SD, Shatsky M, Cohen PS et al. Monoclonal antibody and enzymatic profiles of human malignant T-lymphoid cells and derived cell lines. Cancer Res 1984;44:5657-60.

15 Helseth E, Kowalski M, Gabuzda D et al. Rapid complementation assays measuring replicative potential of human immunodeficiency virus type 1 envelope glycoprotein mutants. J Virol 1990;64:2416-20.
16 Gluzman Y. SV40-transformed Simian cells support the replication of early SV40 mutants. Cell 1981;23:175-82.

17 Seed B, Sheen J-Y. A simple phase-extraction assay for chloramphenicol acyltransferase activity. Gene 1988;67:271-77.

18 Hwang SS, Boyle TJ, Lyerly HK, Cullen BR, et al. Identification of envelope V3 loop as the major determinant of CD4 neutralization sensitivity of HIV-1. Science 1992;257:535-7.

19 Langedijk JPM, Back NKT, Durda PJ, Goudsmit J, Meloen RH. Neutralizing activity of anti-peptide antibodies against the principal neutralization domain of human immunodeficiency virus type 1. J Gen Virol 1991;72:2519-26.

20 Robinson WE Jr, Kawamura T, Lake D et al. Antibodies to the primary immunodominant domain of human immunodeficiency virus type 1 (HIV-1) glycoprotein gp41 enhance HIV-1 infection in vitro. J Virol 1990;64:5301-5.

21 Homsy J, Meyer M, Tateno M, Clarkson S, Levy JA. The Fc and not CD4 receptor mediates antibody enhancement of HIV infection in human cells. Science 1989;244:1357-60.

22 Allan JS et al. Strong association of simian immunodeficiency virus (SIVagm) envelope glycoprotein heterodimers: possible role in receptor-mediated activation. AIDS Res Hum Retrovirus 1992;8:2011-20.

23 Clapham PR, McKnight A, Weiss RA. Human immunodeficiency virus type 2 infection and fusion of CD4-negative human cell lines: induction and enhancement by soluble CD4. J Virol 1992;66:3531-7.

24 Sattentau QJ, Moore JP, Vignaux F, Traincard F, Poignard P. Conformational changes induced in the envelope glycoproteins of the human and simian immunodeficiency viruses by soluble receptor binding. J Virol 1993;67:7383-93.

Received 9 August 1994

Accepted 1 September 1994 
This document is a scanned copy of a printed document. No warranty is given about the accuracy of the copy. Users should refer to the original published version of the material. 